See discussions, stats, and author profiles for this publication at: https://www.researchgate.net/publication/320063086

\title{
Design of aquaponics water monitoring system using Arduino microcontroller
}

Conference Paper in AIP Conference Proceedings · September 2017

DOI: $10.1063 / 1.5002442$

CITATIONS

5 authors, including:

Sohiful Anuar Zainol Murad

Universiti Malaysia Perlis

162 PUBLICATIONS 458 CITATIONS

SEE PROFILE
READS

18,789

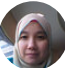

Rohana Sapawi

University Malaysia Sarawak

45 PUBliCATIONS 174 CITATIONS

SEE PROFILE

Some of the authors of this publication are also working on these related projects:

Development of ultra low power RF front-end design for wireless sensor network View project

Wearable Graphene Based Sensor for Determination of Physiological Parameters View project 
Design of aquaponics water monitoring system using Arduino microcontroller

S. A. Z. Murad, A. Harun, S. N. Mohyar, R. Sapawi, and S. Y. Ten

Citation: AIP Conference Proceedings 1885, 020248 (2017); doi: 10.1063/1.5002442

View online: http://dx.doi.org/10.1063/1.5002442

View Table of Contents: http://aip.scitation.org/toc/apc/1885/1

Published by the American Institute of Physics

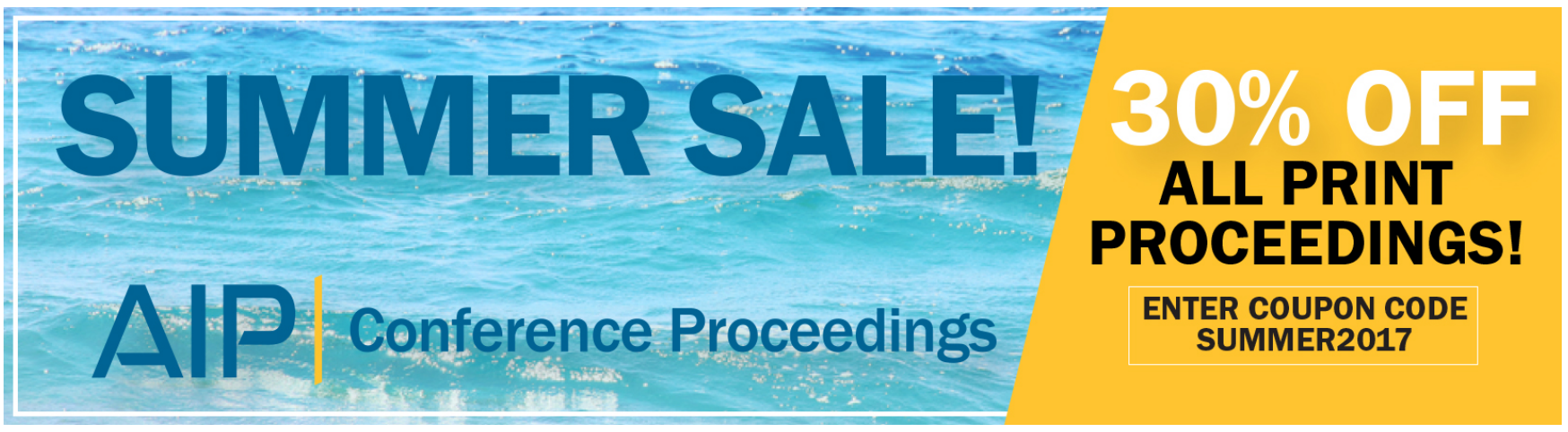




\title{
Design of Aquaponics Water Monitoring System Using Arduino Microcontroller
}

\author{
S A Z Murad ${ }^{1, \mathrm{a})}$, A Harun ${ }^{1, \mathrm{~b})}$, S N Mohyar ${ }^{1, \mathrm{c})}$, R Sapawi ${ }^{2, \mathrm{~d})}$, S Y Ten ${ }^{1, \mathrm{e})}$ \\ ${ }^{I}$ School of Microelectronic Engineering, Universiti Malaysia Perlis , Pauh Putra Campus, \\ 02600 Arau, Perlis, Malaysia. \\ ${ }^{2}$ Department of Electrical and Electronic Engineering, Faculty of Engineering, Universiti Malaysia \\ Sarawak, 94300 Kota Samarahan, Sarawak, Malaysia. \\ ${ }^{a)}$ Corresponding author: sohiful@unimap.edu.my \\ b)aziziharun@unimap.edu.my \\ c)nizammohyar@unimap.edu.my \\ d)srohana@unimas.my \\ e)snow_9yuki@hotmail.com
}

\begin{abstract}
This paper describes the design of aquaponics water monitoring system using Arduino microcontroller. Arduino Development Environment (IDE) software is used to develop a program for the microcontroller to communicate with multiple sensors and other hardware. The circuit of $\mathrm{pH}$ sensor, temperature sensor, water sensor, servo, liquid crystal displays (LCD), peristaltic pump, solar and Global System for Mobile communication (GSM) are constructed and connected to the system. The system powered by a rechargeable battery using solar energy. When the results of $\mathrm{pH}$, temperature and water sensor are out of range, a notification message will be sent to a mobile phone through GSM. If the $\mathrm{pH}$ of water is out of range, peristaltic pump is automatic on to maintain back the $\mathrm{pH}$ value of water. The water sensor is fixed in the siphon outlet water flow to detect water flow from grow bed to the fish tank. In addition, servo is used to auto feeding the fish for every 12 hours. Meanwhile, the LCD is indicated the $\mathrm{pH}$, temperature, siphon outlet water flow and remaining time for the next feeding cycle. The $\mathrm{pH}$ and temperature of water are set in the ranges of 6 to 7 and $25^{\circ} \mathrm{C}$ to $30^{\circ} \mathrm{C}$, respectively.
\end{abstract}

\section{INTRODUCTION}

Water is a special kind of ecological resource which is a foundation to support the ecosystem on earth. Water as an ecosystems not only supports human life and activities, but also helps to maintain the ecological structure, ecological processes and regional ecological environment [1]. Furthermore, water is not a renewable source, but keeps on recycling. Excessive release of wastes such as solid wastes and hazardous wastes into a river and sea as a result of industrialization and urbanization will worsen the quality of water, which can adversely affect the aquatic life [2]. Therefore, to ensure adequate and safe water for all (include environment), Malaysia's Vision 2020 for water is to conserve and manage the country's water resources [3].

Christopher Teh (2011) said that the agriculture sector consumes the most water compared to all other industries. Eighty five percent of the world's water consumption is for agricultural activity, which is at a rate of 235 million liters per second and $70 \%$ of this water consumed is wasted [4]. An aquaponics system could contribute as a possible way to solve this problem by reducing the water usage in agriculture. Aquaponics is a portmanteau of aquaculture and hydroponics which also means an integration of aquaculture and hydroponics environment. Aquaculture is the farming of aquatic organisms such as fish and shellfish, with fish rearing for consumption as primary objective. This could also be referred, as the cultivation of both marine and freshwater species, whose 
production can be ranged from land-based to open-ocean. While for hydroponics, it means growing up plants using mineral nutrient solutions, in water and without soil.

In aquaponics system, the aquatic animals are fed daily. They will digest the food and excrete the waste in the water. Their excretion is broken down into nitrates and nitrites, which are the nutrients for the plants and the water, will be recirculated throughout the system. The plants can be used as a bio filter to remove wastes or uneaten fish feed in water to create a healthy environment [5]. Therefore, soil and mineral fertilizers are not needed in hydroponic bed as crops obtain nutrients from the fish water through their roots [6]. Thus, mutually benefiting both the fish and crop.

Nowadays, people prefer using aquaponics for breeding fish, than hydroponics system and aquaculture, because this system can grow plants and at the same time filter the water from the fish tank. Thus, aquaponics is better than hydroponics and aquaculture system as a balanced ecosystem is created and it is beneficial to both crops and fishes. Therefore, aquaponics system is a win-win situation which also indirectly helps saving cost and significantly reducing the water usage as it is recirculated to be reused.

This work presents a design of aquaponics water monitoring system using Arduino microcontroller to monitor and control the water parameters in the fish tank. The IDE software is used to develop a program for the Arduino to communicate with the sensors and other hardware. The program is implemented to the hardware to test the functionality of the circuit. Since this is a small scale aquaponics system, the amount of energy needed is minimal and thus powered by only a battery.

\section{PROPOSED ARCHITECTURE}

Figure 1 shows a block diagram of the aquaponics system using Arduino microcontroller. The developed program is stored in the microcontroller Arduino Mega board and ready to be executed when needed. The $\mathrm{pH}$ sensor circuit, temperature sensor, water sensor, servo, LCD, GSM and peristaltic pump are connected to the Arduino board. The program and hardware parts of the aquaponics system are combined together to perform the functionality.

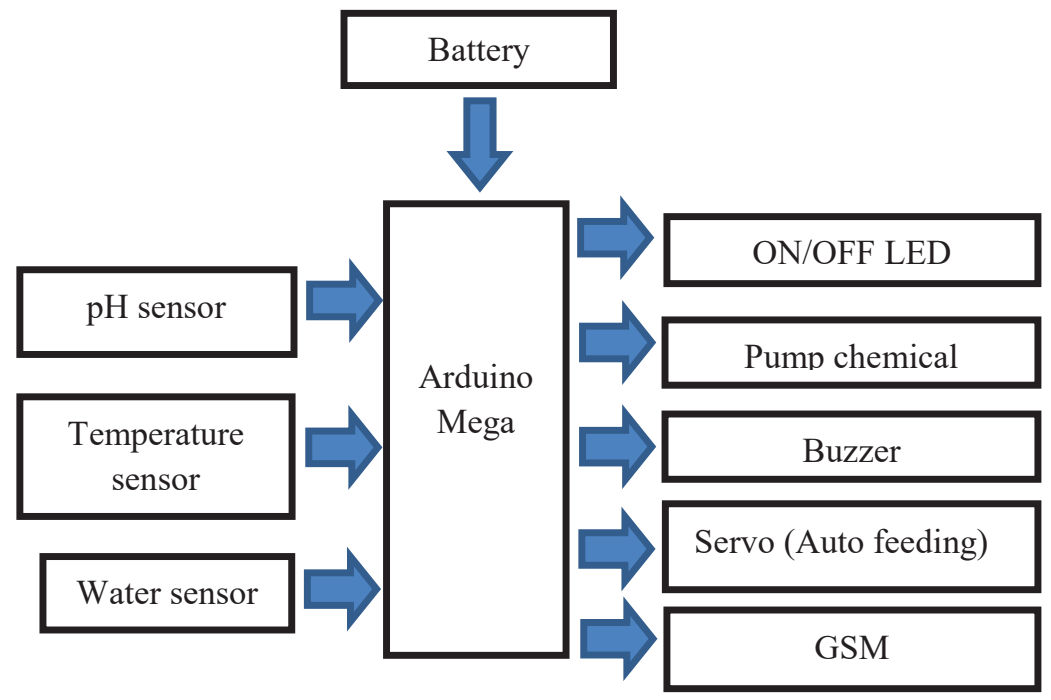

FIGURE 1. Block diagram of aquaponics system using Arduino microcontroller.

The program is started by executing the servo to rotate and feeding the fish by dropping the fish palette to the fish tank. After that, the $\mathrm{pH}$, the temperature and the water sensors will start to function. When the $\mathrm{pH}$ sensor detects the $\mathrm{pH}$ value of water is out of range, LED will light up and trigger the peristaltic pump to pump the chemical solution into the water to maintain the $\mathrm{pH}$ value. Meanwhile, the water sensor is used to detect the water flow into the fish tank through the siphon outlet. If the water flow through a siphon outlet is stopped, the buzzer will be triggered. Therefore, no water is pumped from fish tank to grow bed. When the $\mathrm{pH}$, temperature and water sensor 
are out of the ranges, a message will be sent to a mobile phone through GSM modem for notification. The servo is used to auto feed fish every 12 hours.

The function of $\mathrm{pH}$ sensor is to detect the $\mathrm{pH}$ value of the water. The $\mathrm{pH}$ sensor functionality is constructed by connecting the analog input port of the Arduino board with the sensor circuit board. The $\mathrm{pH}$ sensor circuit consists of three wires which are ground, $+5 \mathrm{~V}$ and analog output. In addition to that, the temperature sensor functionality are also constructed in a similar way. The sensor consists of three wires which are indicated $+5 \mathrm{~V}$ (red), ground (black) and data (yellow). The wires are connected to the Arduino board using a $4.7 \mathrm{k} \Omega$ resistor to form a pull up resistor. Pull up resistor is employed to make sure that the signal will be a valid logic if the peripheral is disconnected or high impedance is introduced. Similarly, the water sensor consists of three wires is connected to $5 \mathrm{~V}$, ground and digital pin 7 of the Arduino board. Additionally, the water sensor is also connected to a buzzer using a transistor. The servo is used in this system to auto feeding fish in the tank. This servo consists of three wires which are yellow, red and black wire. Red wire is connected to $5 \mathrm{~V}$, black wire is connected to ground and yellow is connected to digital pin 12 of the Arduino board. The $\mathrm{pH}$ sensor, temperature sensor, water sensor circuit and servo connection is shown in Fig. 2 .

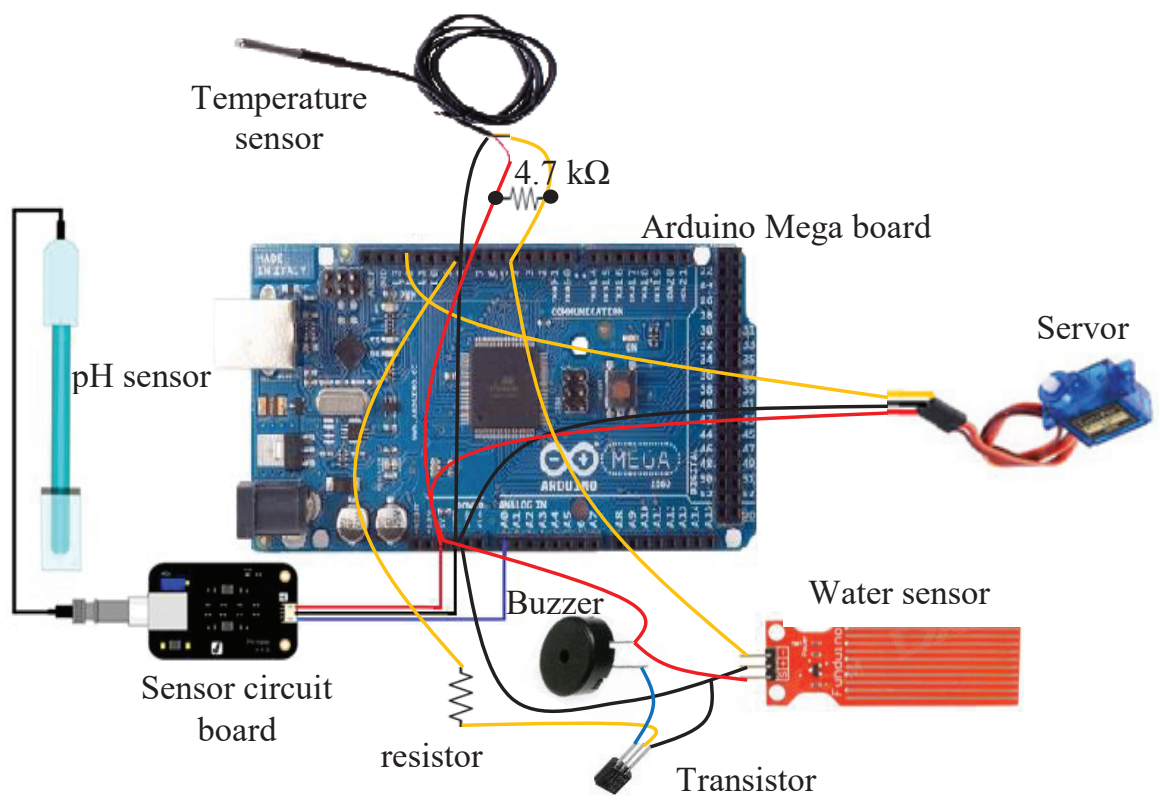

FIGURE 2. pH sensor, temperature sensor, water sensor circuit and servo connection.

A peristaltic pump is used in this system to pump the chemical solution into the fish tank in order to balance back the $\mathrm{pH}$ value of water. This pump is connected in parallel with an 1N4001 diode to protect the Arduino board from reverse electromagnetic force produced by the pump motor. The negative terminal of the diode is connected to a transistor collector for use as current amplification since the Arduino board cannot supply enough current to drive the peristaltic pump. The positive terminal of the pump is connected to a supply voltage. Meanwhile, the base of the transistor is connected to digital pin 9 of the Arduino board and the emitter of the transistor is connected to the ground. The GSM is used in this system to send the notification if the $\mathrm{pH}$ and temperature values are out of ranges and also if the siphon water flow not working. GSM has three wires connection which are black and red colors. The black wire is connected to a ground and the red wire is connected from digital pin 3 to STXD of GSM and another red wire is connected from digital pin 10 to SRXD of GSM. Figure 3 shows the peristaltic pump and the GSM connection circuit. 


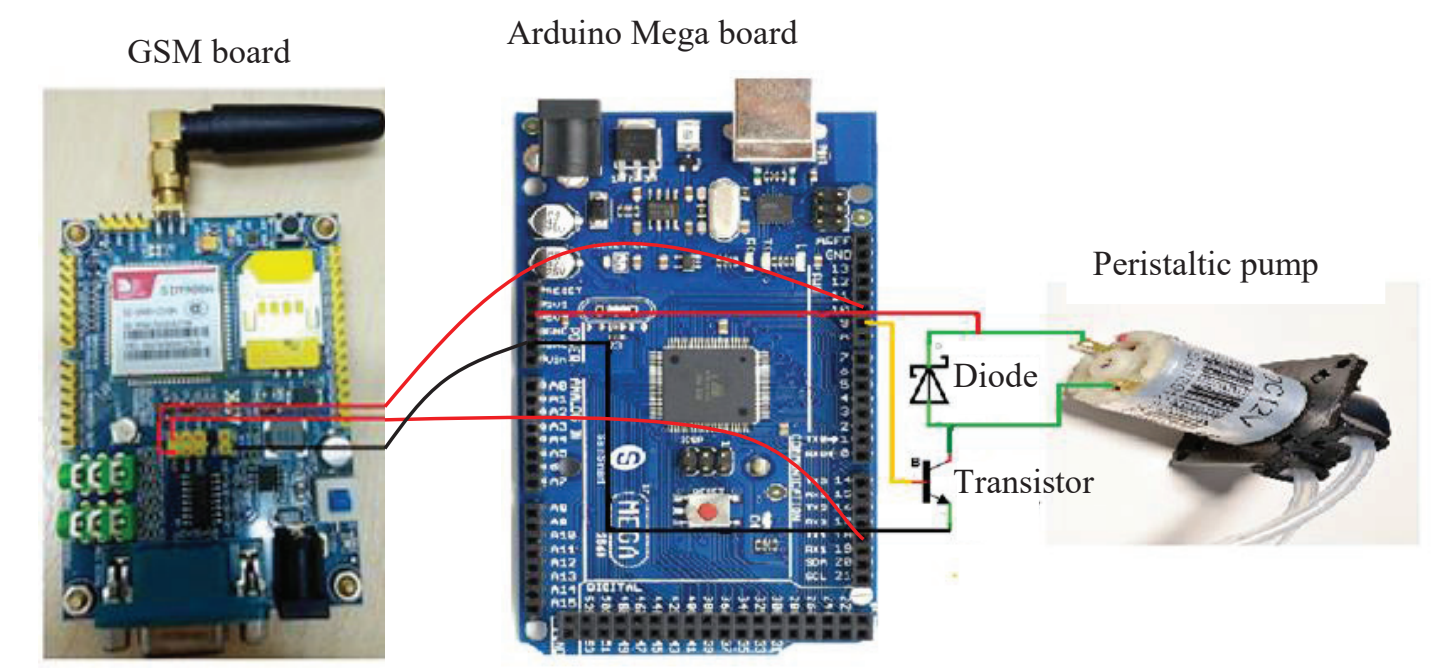

FIGURE 3. Peristaltic pump and the GSM connection circuit.

Liquid crystal display (LCD) with 20 characters $\mathrm{x} 4$ lines is used with an Arduino board to display the water parameters and feeding time cycle. This type of LCD is chosen because four's information is required to be displayed. This LCD consists of 16 pins connector and each pin has its own function. Figure 4 shows LCD connection circuit with FEEDING notification.

Arduino Mega board

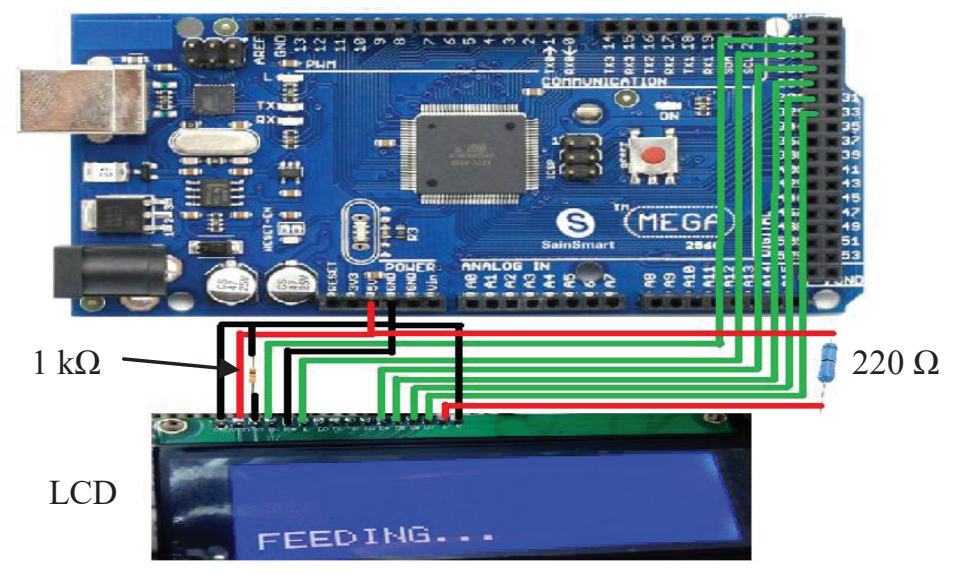

FIGURE 4. LCD connection circuit.

\section{RESULTS}

Figure 5 shows the results of water control and monitor system displayed by the Arduino Serial Monitor. The $\mathrm{pH}$ value and water temperature can be monitored with the LED status ON and OFF. In addition, the status of siphon outlet water flow ON or OFF is also indicated. 


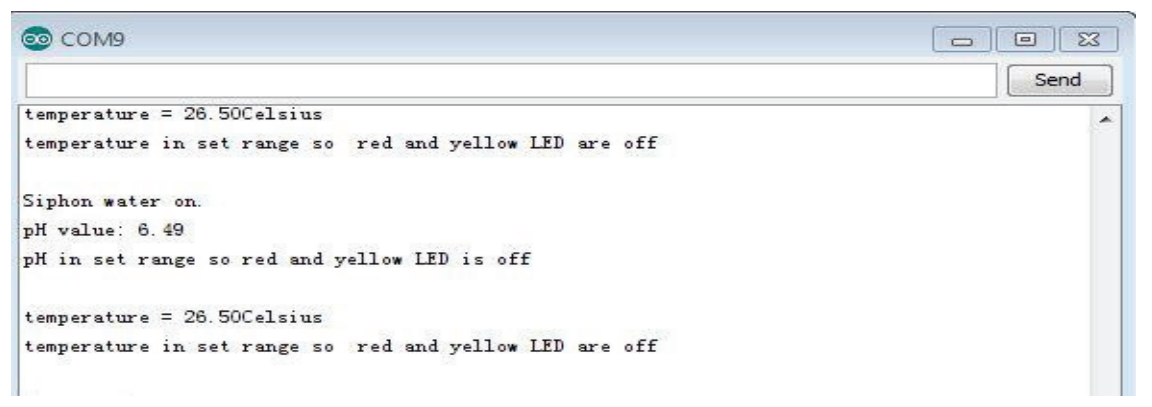

FIGURE 5. Results of temperature, siphon water on and $\mathrm{pH}$ value.

The information displayed on LCD is shown in Fig. 6. The $\mathrm{pH}$ value, the water temperature, the status of siphon outlet water flow and the remaining time for auto feeding can be displayed on the LCD screen at the same time. When the remaining time for the feeding cycle is completed, the LCD will be displayed "FEEDING" on the LCD. Once the feeding is finished, the LCD will show again all the information.

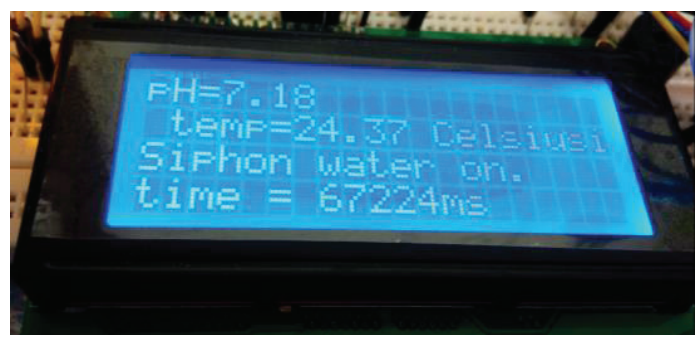

FIGURE 6. Information on LCD.

The range of $\mathrm{pH}$ water values are set between 6.0 to 7.0 [7]. If the $\mathrm{pH}$ water values is out of range, the LED will be lighted up and the peristaltic pump will be turned ON for neutralize the water back to normal. If a red LED is turned ON, the water is too acidic while if a yellow LED is turned ON, the water is too alkaline. Meanwhile, the range of temperature sensor is set between $24{ }^{\circ} \mathrm{C}$ to $28{ }^{\circ} \mathrm{C}$. The LED will be turned ON once it detects the temperature of water is out of ranges. Figure 7 (a) and Fig. 7 (b) show the $\mathrm{pH}$ value and temperature value results, respectively.

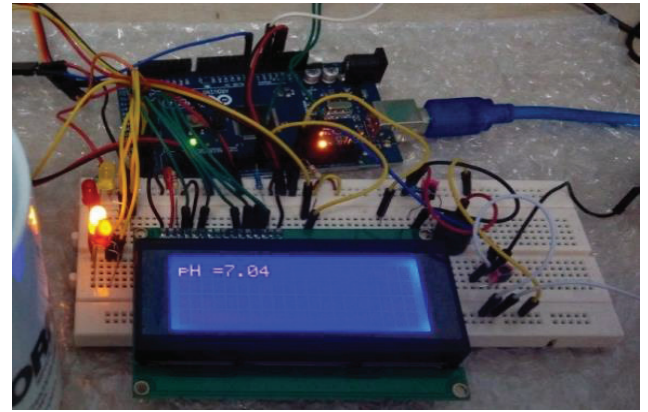

(a) $\mathrm{pH}$ value

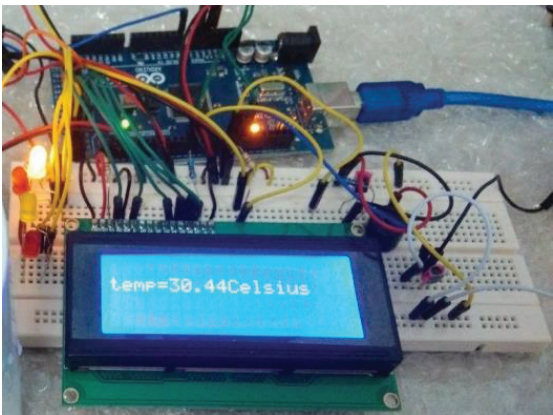

(b) temperature value

FIGURE 7. $\mathrm{pH}$ sensor and temperature sensor testing.

The siphon outlet water flow is monitored using water sensor and the result is observed from the LCD. The siphon outlet water flow is ON when the water flows out from siphon outlet and the buzzer will be turned OFF. However, if the water did not flow, the buzzer will be turned ON. The buzzer sound is notified the people that the water did not flow from the fish tank to grow bed. Figure 8 shows when water flow out from siphon outlet and the LCD displays siphon water ON. 

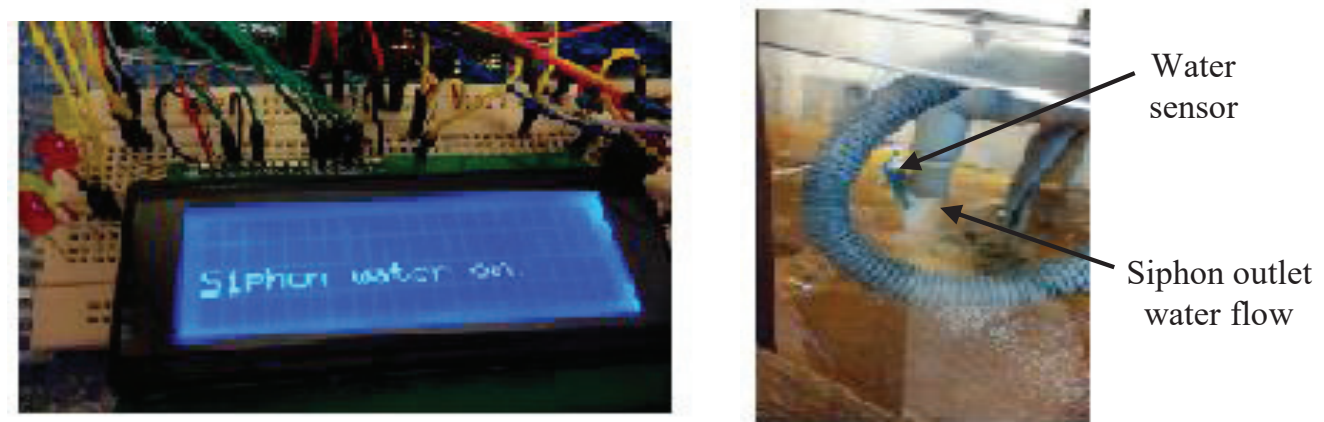

Fish tank

FIGURE 8. Siphon water ON displayed in LCD and water sensor in outlet water flow.

The result of servo is obtained by observing the rotation of the servo. When the servo is rotated, fish palette will be dropped into the fish tank. The servo will able to rotate for maximum $180^{\circ}$. For one feeding cycle, the servo will be rotated 6 times, which three times clockwise and three times anticlockwise. The feeding cycle will be functioned for every 12 hours.

The result of GSM is obtained by observing the message that sent out by the GSM to the mobile phone. The message indicates the condition of water parameters. The water parameters that are required to monitor are $\mathrm{pH}$, temperature and siphon outlet water flow. When the water parameters are out of range, a message will be sent to mobile phone for notification. Figure 9 shows the messages sent out when $\mathrm{pH}$ and temperature is out of ranges and the siphon outlet water is OFF.

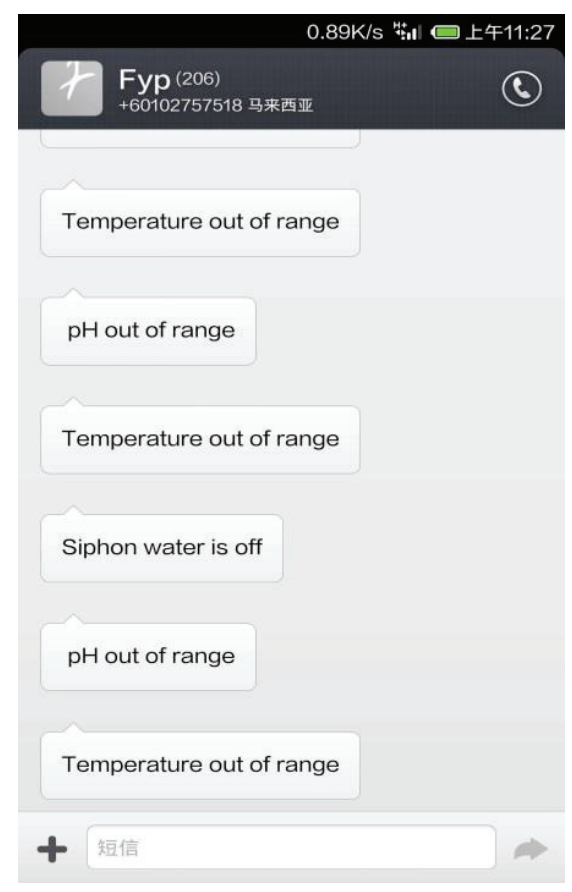

FIGURE 9. Notification on mobile phone.

After ensuring all the sensors or components work well, all the circuits are combined together for performing the aquaponics system functionality test. The circuits that needed to combine are $\mathrm{pH}$ sensor, temperature, water sensor, servo, GSM, LCD, Arduino board and peristaltic pump. All sensors and components are assembly together to produce a prototype. Figure 10 shows the prototype of aquaponics water monitoring system using Arduino microcontroller. 


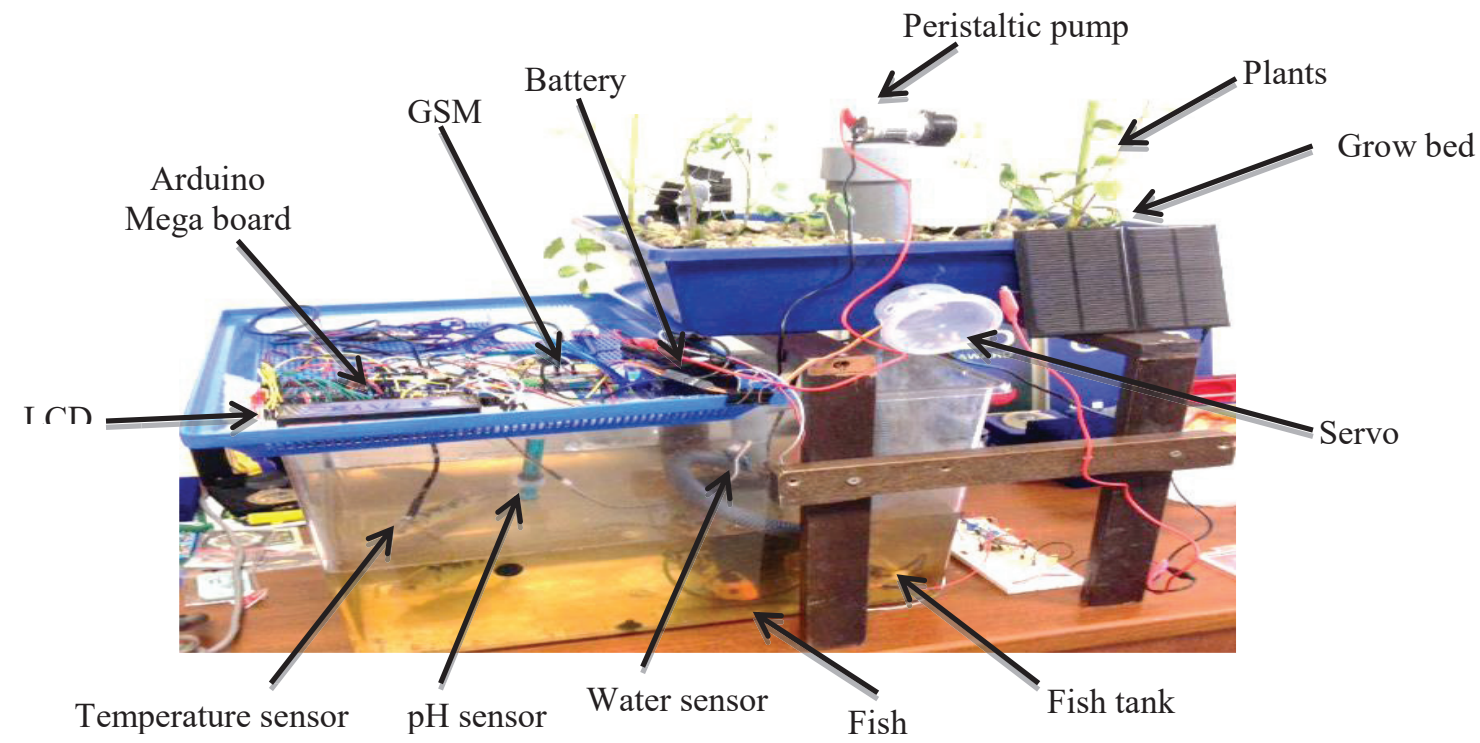

FIGURE 10. Prototype of aquaponics water monitoring system.

\section{CONCLUSIONS}

A low cost aquaponics system using Arduino microcontroller is successfully designed. The program of Arduino IDE is developed to monitor and control the water parameters. The system developed is capable of detecting $\mathrm{pH}$ value, water temperature, siphon outlet water flow, servo, peristaltic pump and using GSM to send message to mobile phone. When the $\mathrm{pH}$ of water is out of range, the peristaltic pump and LED is turned ON, meanwhile when the temperature of water is out of range, the LED is turned ON. In addition, messages will be sent out to mobile phone for notification when $\mathrm{pH}$, temperature and siphon outlet water flow are out of range through GSM. Moreover, the servo can feed the fishes automatically for particular time setting. The aquaponics system using Arduino microcontroller has been successfully developed to monitor the water parameters and control the whole system.

\section{ACKNOWLEDGMENTS}

The authors would like to acknowledge the financial support obtained from the School of Microelectronic Engineering, UniMAP to complete this final year project.

\section{REFERENCES}

1. Yang Liu and Dan Shen, "Assessment on the value of ecosystem service of important protected area for water supply of city," in 2011 Second International Conference on Mechanic Automation and Control Engineering, 2011, pp. 2962-2966.

2. Maria Jose Palma Lampreia dos Santos, "Smart Cities and Urban Areas- Aquaponics as Innovative Urban Agriculture", in Urban Forestry \& Urban Greening 2016, vol. 20, pp. 402-406.

3. S. Jones, "Evolution of Aquaponics," in Aquaponics J., vol. 6, no. 1, 2002.

4. Jung-Yuan Liang, Yew-Hu Chien, "Effects of feeding frequency and photoperiod on water quality and crop production in a tilapia-water spinach raft aquaponics system", in International Biodeterioration \& Biodegradation 2013, vol. 85, pp. 693-700.

5. Sumeth Wongkiew, Zhen Hu, Kartik Chandran, Jae Woo Lee, Samir Kumar Khanal, "Nitrogen Transformations in Aquaponic Systems: A Review", in Aquacultural Engineering 2017, vol. 76, pp. 9-19.

6. Shah Abd Hafiz Zainal Abidin and S. Noorjannah Ibrahim, "Web-based Monitoring for an Automated Fertigation System: An IoT Application", in IEEE $12^{\text {th }}$ Malaysia International Conference on Communications (MICC), Kuching, Malaysia, 23-25 Nov., 2015.

7. Brunno da Silva Cerozi, Kevin Fitzsimmons, " The Effect of $\mathrm{pH}$ on Phosphorus Availability and Speciation in an Aquaponics Nutrient Solution", in Bioresource Technology 2016, vol. 219, pp. 778-781. 